\title{
Ciudad: Espacio público y ciudadanía (desde la perspectiva geográfica)
}

\section{Zaida Liz Patiño Gómez*}

Resumen. El presente trabajo se enmarca dentro de la discusión sobre el espacio. Se pretendió definir elementos desde la geografía urbana para hacer una lectura del Plan de Ordenamiento Territorial -POT- de Bogotá, resaltando la importancia de la perspectiva geográfica y las consecuencias posibles de no haber sido tenida en cuenta respecto a las interpretaciones epistemológicas y metodológicas que se han desarrollado desde la teoría social, elemento crucial para cualificar esta herramienta de ordenación del espacio. Se propone entonces abordar el tema de la ciudad a través de la revaloración del espacio público en su doble sentido: físico y jurídico político e invita a refundar nuestras ciudades a partir del ejercicio de la ciudadanía en el espacio para lo público. Palabras clave: geografía urbana, teoría social, espacio público, participación ciudadana, POT de Bogotá.

* Socióloga Universidad Nacional de Colombia. Magíster en Geografía, énfasis en Ordenamiento Territorial. Convenio UPTC-IGAC, Bogotá. Docente Universidad de Ciencias Aplicadas y Ambientales -UDCA- 


\begin{abstract}
This work is based within the discussion of the space. With this we tried to define elements from the urban geography to make a reading of the Bogota Territorial Arranging Plan -POT-, standing out the importance of the geographic perspective and the possible consequences if it was not taken into account with respect to the epistemological and methodological interpretations and which has been developed from the social theory, crucial element to qualify this tool of arrangement of the public space. It has also as objective to undertake the city subject by means of the revalue of the public space in its double sense: physical and political juridical and it invites to refund our cities from the exercise of the citizenship in the space for the public. Key Word: urban geography, social theory, public space, citizenship participation, POT from Bogotá.

Resumé. Ce travail est encadré dedans la discussion de l'espace. Avec ceci, on prétends définir éléments dès la géographie urbaine pour faire une lecture du Plan d'Ordonnance Territoriale -POT de Bogotá, mettant en relief l'importance de la perspective géographique et les possibles conséquences de n'avoir pas eu en compte au rapport des intérpretations épistemologic et méthodologic qui se sont dévelopés dès la théorie sociale, élément crucial pour qualifier cet outil d'ordonnation de l'espace. Alors on propose aborder le thème de la ville à travers de la revalorisation de l'espace publique dans son double sense: physique et juridique politique et invite à refonder nos villes a partir de l'exercise de la citoyénneté dans l'espace pour le publique. Mots clé: géographie urbaine, théorie sociale, espace publique, participation de la citoyénneté, POT de Bogotá.
\end{abstract}

Aceptado : junio 2003.

124 Zaida Liz Patiño Gómez 


\section{Introducción}

La Constitución Nacional de Colombia se enmarca dentro de un ámbito jurídico, democrático y participativo garante de un orden político, económico y social justo. En el artículo segundo plantea que uno de los fines del Estado es "facilitar la participación de todos en las decisiones, que los afectan en la vida económica, política, administrativa y cultural de la nación".

Posterior a la Constitución Nacional del 91, se concibe la primera Política Urbana Ciudades y Ciudadanía, en 1995; la cual pretende redimir las ciudades colombianas, en las cuales viven cerca de 25 millones de personas, que representan el $70 \%$ de la población total del país, según cifras del Ministerio de Desarrollo Económico. En 1997 se expide la Ley 388 de Ordenamiento Territorial, que al ser nacional, obliga a la planeación y a extender su plazo a 10 años -trascendiendo cualquier ámbito de gobierno limitado-. Esta ley va a tener por lo tanto una trascendencia enorme en la gestión espacial de la ciudad.

Dentro de este marco, dos son las pretensiones de esta investigación. En primer lugar, el trabajo busca definir elementos desde la geografía, específicamente la geografía urbana, para hacer una lectura del Plan de Ordenamiento Territorial -POT- de Bogotá, para resaltar lo importante que es la mirada de la disciplina y la trascendencia enorme de no haber tenido en cuenta las interpretaciones teóricas y metodológicas que se han desarrollado desde la teoría social, fundamental si se quiere ordenar el espacio urbano a través de la participación ciudadana.

La segunda, mostrar que la geografía -por lo menos en Bogotá- como ciencia social, tampoco ha dicho mucho sobre la espacialización del espacio urbano a la luz del desarrollo de la teoría social en el mundo y menos aún desde la perspectiva del abordaje del espacio público como ciudadanía, como se desarrolla en esta investigación.

Al estudiar la Ley de Ordenamiento Territorial -de gran significación para la vida y la existencia de la mayoría de la población colombiana- y trasladándose a su consecuencia directa, el POT de Bogotá, se encuentra que la geografía y sus desarrollos contemporáneos no han sido tenidos en cuenta para cualificar la planeación del territorio de la ciudad. Más allá de la aplicación de los Sistemas de Información Geográfica -SIG- y demás herramientas cartográficas, la geografía no jugó un papel fundamental en su elaboración, habiendo podido contribuir pensando la ciudad y complejizando el abordaje del problema urbano, especialmente desde temáticas como la exclusión en la ciudad, la desigualdad, la inequidad, el género y la participación ciudadana. Como consecuencia 
de esto, el plan adolece de elementos que habiendo sido abordados desde la geografía redundarían en una mayor calidad de vida para la gente.

En cuanto a la revisión del estado del arte de la producción geográfica en Bogotá, se observa un desarrollo incipiente sobre la problemática urbana desde la perspectiva de la teoría social y el Espacio Público. Conclusión a la que se llega luego de explorar la producción del pregrado del Departamento de Geografía de la Universidad Nacional; la producción de la Maestría en Geografía -EPG-; la biblioteca del Instituto Geográfico Agustín Codazzi -IGAC- y la producción de la Licenciatura en Educación básica con énfasis en Ciencias Sociales y de la Maestría en Docencia de la Geografía de la Universidad Pedagógica Nacional.

Finalmente esta investigación invita a abrir de manera conciente la actitud desde la geografía para contribuir a la interpretación del fenómeno urbano. Se desarrollan entonces unos elementos seminales para el abordaje y complejización del tema urbano, entre otras cosas porque sin el aporte de la Geografía urbana, los actores que hacen la planeación hacia el futuro (el Estado, el capital privado y la sociedad civil) se quedarán cortos en un discurso de la disciplina que aportaría a la cualificación efectiva del lenguaje y los métodos de acercamiento a la cuestión urbana.

\section{El espacio desde la teoría social}

$\mathrm{Al}$ igual que otras ciencias, la Geografía ha atravesado por profundas crisis respecto a sus paradigmas, su objeto de estudio y su epistemología. La evolución del concepto mismo de espacio ha pasado de las posturas netamente físico-naturalistas a su concepción como espacio social concebido en el modernismo y asumido desde variadas perspectivas teóricas como la del materialismo dialéctico, el funcionalismo, el estructuralismo, hasta las posturas posmodernas.

En el siguiente aparte se pretende rescatar el aporte teórico de autores que sin ser todos geógrafos, han permeado el discurso de la disciplina. Esta visión nos acerca a la mirada que queremos revalorar en el análisis del espacio urbano, estos es, el Espacio Público como ciudadanía.

Se hace necesario comenzar con la afirmación de Manuel Castells (1978), en la que señala la importancia de asumir la discusión sobre el espacio a partir de la teoría social, dado que los procesos sociales producen el espacio y estos deben ser analizados a la luz de dicha teoría.

En este orden de ideas, es el espacio relacional el que aquí nos concierne. Un espacio que no es simple receptáculo sino una interrelación entre objetos y acciones como diría Santos (2000). Asumirlo como un todo en el

126 Zaida Liz Patiño Gómez 
cual hacen parte los objetos tanto naturales como artificiales, junto con las acciones y sistemas de acciones que en él se dan lugar, nos permite dilucidar su carácter histórico, lo que se traduce en su concepción como producto social.

Giddens (citado por Santos, 2000) distingue entre acto, acción y actuación. Un acto sería un segmento identificado de una acción. Esta se daría como un conjunto de actos o como un proceso formado de subprocesos, actos consecutivos. No es posible comprender los sistemas de objetos separados de los sistemas de acciones, y estos tampoco se dan sin los primeros. La existencia de cada uno está mediada por la del otro, "por un lado, los sistemas de objetos condicionan la forma en que se dan las acciones y, por otro lado, el sistema de acciones lleva a la creación de objetos nuevos o se realiza sobre objetos preexistentes. Así, el espacio encuentra su dinámica y se transforma" (Santos, 2000:56). Sin embargo, no existe total armonía entre los sistemas de objetos y los sistemas de acciones, y son precisamente las contradicciones y tensiones entre ellos, lo que anima los cambios cualitativos del espacio geográfico.

Lejos de haber una definición unívoca del espacio se debe recalcar precisamente su naturaleza cambiante, tanto en su contenido como en su definición, esto es gracias a que cada tiempo histórico lleva consigo una objetivación diferente del concepto espacial domi- nante y la variabilidad conceptual, trae consigo cambios objetivos, como lo señala Harvey (1990).

Así, ante la ausencia de una definición única y objetiva, es necesario insistir en el reconocimiento de las múltiples cualidades que el tiempo y el espacio pueden expresar, y el rol de las prácticas humanas en su construcción; prácticas que, para el análisis del espacio no pueden ser obviadas, dado que es su análisis el que nos puede acercar de forma más precisa a su comprensión.

\subsection{El espacio en el capitalismo}

Este ha sido un tema abordado recurrentemente por diversos autores dentro de la teoría social, tales como H. Lefebvre, D. Harvey, M. Castells, M. Santos y A. Giddens. Aunque algunas de estas posturas están influenciadas por la concepción marxista -revalorada en los tiempos posmodernos-, parte de los planteamientos generales conservan vigencia o han sido complementados por otros autores. Castells por su parte ha autocriticado sus posturas radicales sobre la producción del espacio bajo la perspectiva del materialismodialéctico y ha introducido cambios en su teoría, cobrando mayor importancia los actores sociales que le proporcionan existencia, desplazando el determinismo de las condiciones económicas de producción y reproducción. 
La característica expansiva del capitalismo nunca antes se había manifestado con mayor claridad como en la llamada globalización, estadio actual del capitalismo, en la que todos los confines de la tierra perpetúan su existencia, modelándose de acuerdo con las necesidades que conllevan su reproducción. Estas se refieren a la producción de espacialidades específicas para la atracción del capital financiero; dinámica producto de la competitividad, cada vez mas creciente, entre lugares y territorios en busca del desarrollo en el marco de la lógica hegemónica.

La democracia dentro del sistema capitalista, plantea profundas contradicciones sociales dada la particular naturaleza de este último. Los preceptos de igualdad, equidad y justicia, lejos están de la realidad actual donde las necesidades insatisfechas, la pobreza, la injusticia, la inequidad son pan de cada día, productos de la dinámica capitalista.

\subsubsection{El espacio en Lefebvre}

Este autor parte de tres elementos para explicar su concepción de lo urbano: el espacio, la cotidianidad y la reproducción capitalista de las relaciones sociales. Los tres, de manera integral, explican las características urbanas. El espacio no puede ser explicado sin tener en cuenta la dinámica de los protagonistas que la viven, e igualmente no se sustraen a su explicación las relaciones que intervienen dentro de la reproducción del sistema.
En el espacio, se efectúa la apropiación de los bienes producidos en la sociedad capitalista y por ser este el ámbito de la reproducción de la vida cotidiana, es el escenario en el que se vislumbran la alienación y el desequilibrio social, dada la manera dispar en que sus habitantes satisfacen sus necesidades, resultado de la misma lógica del capital.

Las razones teóricas de la pasividad (ausencia de participación) para Lefebvre (1983) se distinguen precisamente en la fragmentación del fenómeno urbano. Aquella que permite que el espacio se divida para su intercambio como mercancía produciendo un freno el pensamiento arquitectónico y urbanístico, así como la consecuente invisibilidad del habitante.

Su análisis del espacio parte del concepto de modo de producción, distinguiendo dos elementos que lo componen: lo urbano, que se expresa en los problemas de crecimiento de la ciudad, y lo cotidiano, que es el ámbito de la alienación producto de un consumo programado, propio del sistema capitalista.

Expresa en su teoría, que el espacio es el lugar en el cual se reproduce la sociedad en su conjunto y por ello es el sitio de grandes confrontaciones políticas. Esto se explica porque el capitalismo es un modo de producción que penetra todos los ámbitos de la vida social, incluyendo el mun-

128 Zaida Liz Patiño Gómez 
do de lo cotidiano; de aquí se deriva una contradicción básica que se produce entre ganancia capitalista y necesidad social la cual se refleja en el espacio.

Los conflictos urbanos que se originan por el uso del espacio y por el dominio en la vida cotidiana, constituyen para este autor los más significativos de los tiempos modernos. Estos no confrontan únicamente al trabajo con el capital, sino que enfrentan a este último con una situación más amplia: las necesidades sociales.

Lefebvre aboga por la liberación humana en la ciudad. Plantea que la alienación de la vida cotidiana -propia de la ciudad industrial- desaparecerá cuando los seres humanos tengan la posibilidad de crear la ciudad como una obra, apropiándosela en un contexto en el cual se rompa con la intermediación de los valores de cambio y sólo rija la apropiación de los valores de uso.

El mundo de la vida cotidiana, es el punto de partida para toda práctica liberadora porque es allí mismo donde se esbozan las verdaderas creaciones humanas, la cultura, los estilos y formas de vida. Allí, nos dice el autor, se opera la renovación incesante del ser humano. Pero en lo cotidiano se debe dar la ruptura ideológica que extermine la enajenación, ella lo reconstituiría en su libertad y espontaneidad.

\subsubsection{El espacio en David Harvey}

Este autor retoma la teoría de Lefebvre según la cual el dominio sobre el espacio constituye una fuente fundamental y omnipresente del poder social sobre la vida cotidiana, con el fin de exponer su hipótesis acerca de que en las economías monetarias en general, y en la sociedad capitalista en particular, el dominio simultáneo del tiempo y el espacio constituye un elemento sustancial del poder social. En sus palabras “(...) es evidente que la hegemonía ideológica y política en cualquier sociedad depende de la capacidad de controlar el contexto material de la experiencia personal y social" (Harvey, 1990:252).

Este autor considera el capitalismo como un modo de producción revolucionario en el cual las prácticas materiales y los procesos de reproducción social están siempre transformándose. De esta manera, los cambios conceptuales derivados de esas transformaciones explican a su vez los cambios objetivos y en los significados del tiempo y el espacio. Si el avance del conocimiento científico, técnico, administrativo, burocrático y racional es vital para el progreso de la producción y el consumo capitalistas, entonces los cambios en nuestro aparato conceptual (incluso las representaciones del espacio y tiempo) pueden tener consecuencias materiales para el ordenamiento de la vida diaria (Harvey, 1990). 
En la época actual denominada del capitalismo global prima el incentivo para crear un mercado mundial, reduciendo las barreras espaciales, aniquilando las fronteras y racionalizando la organización espacial de acuerdo a los intereses propios de la reproducción capitalista. Esto se concreta en configuraciones territoriales productivamente eficientes, redes de circulación (sistemas de transporte y comunicaciones) y consumo (instalación de los hogares y casas, organización de la comunidad y diferenciación residencial, consumo colectivo, sistemas de mercados).

En este orden de ideas, para Harvey las prácticas espaciales y temporales nunca son neutrales en las cuestiones sociales, siempre expresan algún tipo de contenido de clase o social y, en la mayor parte de los casos, constituyen el núcleo de intensas luchas sociales.

\subsubsection{El espacio en Manuel Castells}

En su teoría es fundamental la revaloración de los seres humanos en la construcción de su presente y futuro. Si bien Lefebvre rescató la perspectiva humana dentro de la cotidianidad, ella se había perdido en las posturas posteriores y sólo vuelve a aparecer, con la reconsideración de Castells frente a la incapacidad de la teoría marxista para explicar la dinámica social humana y su incidencia en la transformación del espacio. Dada su ortodoxia económica se queda corta en el análisis de fenómenos que no son producto de las relaciones de producción ni de la lucha de clases, entre ellas la inequidad de género, las perspectivas étnicas, nacionalistas, religiosas, entre otras.

En su análisis (Castells, 1986), parte de la base que, únicamente a partir del estudio de las relaciones entre la gente y la urbanización podremos entender las ciudades y a los ciudadanos al mismo tiempo. Lo urbano aparece entonces como resultado de las acciones conscientes de los individuos y grupos sociales en la conformación de la ciudad a la imagen y semejanza de sus elecciones. Los movimientos urbanos son fuente del cambio en la estructura urbana, en la medida que éste es resultado de sus movilizaciones y reivindicaciones frente al orden instituido.

Se pueden considerar como las principales hipótesis del trabajo de Castells:

- La ciudad es un producto social resultante de intereses y valores sociales en pugna.

- Como los intereses socialmente dominantes han sido institucionalizados $y$ se oponen al cambio, las innovaciones principales de la función de la ciudad, de su significado y su estructura, suelen ser consecuencia de la movilización y exigencia de las bases populares.

- El proceso de cambio social urbano no puede reducirse a los efectos pro-

130 Zaida Liz Patiño Gómez 
ducidos en la ciudad por los movimientos sociales victoriosos. Por lo tanto, una teoría del cambio urbano debe explicar la transformación que obedece tanto a la acción de los intereses dominantes como a la resistencia y el desafío que oponen las bases populares a esa dominación.

- Por último, aunque las relaciones entre las clases y la propia lucha de clases son fundamentales para entender el proceso de los conflictos urbanos, no son la única causa, ni la principal del cambio social urbano. Existen otras causas de cambio social relacionadas con la función autónoma del Estado, las relaciones entre los sexos, los movimientos étnicos y nacionales y los que se autodenominan como movimientos sociales urbanos.

Los objetivos centrales de los movimientos sociales urbanos comparten la búsqueda del acceso satisfactorio al consumo colectivo; la lucha por la defensa de la identidad colectiva, que se traduce en identidad citadina como conjunto de diversas apuestas culturales reunidas en un mismo ámbito: la ciudad; la participación en la toma de decisiones y el logro de espacios de autogestión en las decisiones administrativas y políticas que afectan a la comunidad.

La importancia de los movimientos sociales urbanos radica en su poder para generar el cambio social. El ámbito de la sociedad civil -nivel donde actúan los movimientos sociales- es el escenario donde se contrastan los sistemas valorativos de las clases o grupos en pugna, siendo estos la clase dominante y los movimientos sociales. En la medida que los valores de la clase dominante se encuentren o no legitimados, los movimientos sociales actúan como fuente transformadora del significado urbano.

\subsubsection{El espacio urbano hoy en la teoría social}

El conocimiento, como fuente prolífica de cambio, genera transformaciones en las estructuras objetivas. El cambio es producto de crisis y la teoría social ha sido testigo de las que han sufrido los viejos paradigmas, así como la consecuente construcción de los nuevos. Se ha expresado un cuestionamiento a todas las interpretaciones que terminaron por aprisionar la conducta y acción humana en diferentes encrucijadas de acuerdo a cada teoría, fuera ésta funcionalista, marxista, evolucionista, estructuralista u otra. El nuevo paradigma se da en pro de la liberación de los actores, de su emancipación en el marco de la acción humana.

A mediados de la década de los setenta surgen movimientos sociales (feministas, étnicos, religiosos, de amor libre, opción sexual, etc.) que pretendían la reivindicación de un espacio para todas las apuestas culturales. La discusión a partir de las últimas concepciones acerca del espacio resalta el papel de estos movimientos en la lucha política urbana y la construcción de la ciudad. 
La lucha política de los diferentes actores urbanos tiene como propósito la transformación del significado urbano por quienes viven y conviven, en y con la ciudad; de aquellos que padecen la exclusión, la opresión, la marginalidad, la segregación y la inequidad en el espacio urbano. Los protagonistas urbanos son tenidos hoy en cuenta como factores de cambio de su propia realidad, como grupos con una amplia base social cuyo objetivo es operar cambios en las relaciones sociales de dominación en la sociedad y en la ciudad capitalista.

En este contexto y como se desarrollará en las siguientes líneas, el Espacio Público se erige como el lugar de la transformación agenciada por los movimientos sociales; es el continente para la expresión de las diferentes apuestas de la sociedad civil.

Comprender la doble acepción del Espacio Público en su sentido físico y como espacio de expresión de la otredad, permite potenciar un atributo urbano que, en tanto lugar para el ejercicio de la ciudadanía, cualifica la vida del habitante de la ciudad.

\section{La reivindicación del espacio público. La utopia de ciudad}

La refundación de una nueva ciudad no se refiere exclusivamente a la transformación física de las actuales sino a todo un cambio en la forma de existir que las ha caracterizado hasta ahora. La reconfiguración de nuestra esencia política, su renovación, la transformación de esas formas de pensar -o de no pensar- que hoy convierte a la ciudadanía en ente pasivo, sujeto para amoldar -no para participar-, que de forma conformista acata - muchas veces sin aceptar o comprender- las normas, indicaciones o lineamientos de quienes están en el poder. La revolución entonces implica el asumir consciente de lo que significa ser ciudadano; como diría Castoriadis (1999:163) "aquel que es 'capaz de gobernar y de ser gobernado' (Aristóteles). Pero es también, como ya he dicho, una condición positiva del buen vivir de cada cual, que depende de la 'cualidad' de los demás. Y la realización de este objetivo, ayuda a los individuos para que puedan ser autónomos, la paideia en la aceptación más fuerte y profunda del término, es imposible sin decisiones políticas sustantivas -que, por otro lado-, no pueden dejar de ser tomadas en todo tipo de régimen y en cualquier caso".

La cuestión es ¿dónde y cómo hacer ciudadanía? La respuesta es el Espacio Público. Este que, en tanto continente por antonomasia para el ejercicio de la diferencia, es el lugar de los movimientos sociales, de la cotidianidad, de la lucha y la transformación. 


\subsection{El sentido de lo público}

Partiendo de su génesis, se distingue entre la esfera doméstica (el oikos: la casa, lo heredado) y la esfera pública (la ecclesía: esfera pública/pública). A la primera pertenece la dimensión del hogar y la resolución de las necesidades inmediatas básicas. La esfera pública por su parte, se asocia con el tratamiento de los asuntos comunes por parte de la ciudadanía libre, es el espacio para la toma de decisiones. A partir de esta distinción son recurrentes tres sentidos asociados al duo público-privado según la escritora latinoamericana Nora Rabotnikof (1993: 76): “a) lo que es de interés o de utilidad común a todos, que atañe al colectivo, que concierne a la comunidad y por ende la autoridad de allí emanada vs. aquello que se refiere a la utilidad y el interés individual; b) lo que es visible y se desarrolla a la luz del día, lo manifiesto y ostensible vs. aquello que es secreto, preservado, oculto, $y, c)$-que puede resultar una derivación de los dos anteriores- lo que es de uso común, accesible a todos y por lo tanto abierto vs. aquello cerrado, que se sustrae a la disposición de los otros".

Otros sentidos que se sumarán a la distinción serán: “a) el predominio de la palabra sobre otros instrumentos de poder, el pensar las cuestiones y los Espacio Públicos como ámbito de despliegue de la persuasión a través de la argumentación; b) la necesidad de recurrir a una imagen espacial, que coincide históricamente con una reorganización del espacio social alrededor de la plaza; c) la constitución de la identidad de los moradores del Espacio Público o 'del público' a partir de una igualdad ciudadana definida como isonomía, de igualación en la ley y en la participación en el poder; d) el control público constante tanto sobre las creaciones espirituales como sobre las magistraturas; e) la idea de ley escrita, que se deslinda del arbitrio individual y del arcano, concibiéndose así reglas comunes, públicamente consagradas" (Rabotnikof, 1993: 76).

En los siglos XVII y XVIII, de la identificación de lo común con un Estado que se reserva de la publicidad, se avanza hacia la afinidad de lo público con lo social, entendido como conjunto de individuos. Lo público como asunto de un "público" (privados reunidos en calidad de público) atravesaría por los estadios de la parlamentarización y los inicios del Estado de Derecho, que daría paso a la "opinión pública" y posteriormente a los "encuentros públicos" sobre los que se fundamentarían los partidos políticos como representantes de la comunidad. Finalmente se otorgaría legalidad institucional a ese público a través de la participación en la vida colectiva.

Al incorporarse los espacios público y privado se concede al común las herramientas para ejercer lo público: prensa, asociación, manifestación y derecho a la expresión política a través de sufragio. 
Para el caso de Latinoamérica y Colombia se presencia el momento del cambio, de las redefiniciones políticas que instituyen la participación ciudadana como una nueva forma de hacer política con perspectiva democrática.

Pero, ¿qué democracia? Se pregunta Castoriadis (1999) frente a las democracias actuales. Usando sus planteamientos, la democracia es el poder de la colectividad y en este mismo orden es el régimen de la autolimitación continua. La democracia hace seres humanos libres porque sólo en la medida que se participe en la determinación de las leyes se es realmente autónomo. No es la "igualdad de condiciones" -que lo deja abierto a condiciones de cualquier tipolo que define la democracia, esta cobra significación en la medida que se traduce en la igualdad en el reparto del poder y de las posibilidades de participación en la toma de decisiones políticas.

La invocación a la restitución de lo público en América Latina deviene de la necesidad de refundar la democracia en los pueblos. Las anquilosadas maquinarias políticas que han manejado la vida de los habitantes están destinadas a desaparecer, cada vez cobra mayor fuerza la necesidad de una ciudadanía que asuma las riendas de su futuro. Más aún cuando esas viejas maquinarias demostraron su incapacidad para resolver los problemas más agobiantes de la comunidad.

Caracterizadas por la exclusión, la segregación, la injusticia y la inequidad, la sociedad demanda la recuperación del sentido colectivo -de pertenencia, valores comunes, tradiciones compartidas-, la reivindicación de lo público. Urge entonces una redefinición donde la propuesta apunta a la reforma democrática del Estado y al fortalecimiento de la participación ciudadana en la decisión y gestión de los asuntos públicos.

La creación de una nueva cultura política que permita superar los escollos del "provincialismo" político, fuente del clientelismo, la corrupción y la apatía ciudadana, implica la atención en varios frentes: primero, el rescate del espíritu de civilidad a través del fortalecimiento del Espacio Público como el espacio de la sociedad civil, lugar para su aparición y expresión. En segundo lugar, la legitimación del Estado, su fortalecimiento como garante de los derechos establecidos, generador de las condiciones para el ejercicio de la democracia más allá del sufragio y contrario a toda forma de exclusión, segregación o detrimento de la igualdad. Por último, la nueva propuesta cultural y política pasa por el autoanálisis de la forma misma en que la ciudadanía ha hecho parte de la política y ha reproducido las condiciones para la doble moralidad colectiva y las prácticas negativas (la cultura del atajo y la corrupción son ejemplos de ellas) tan arraigadas en nuestra sociedad.

En este orden de ideas, la utopía de sociedad precisa del compromiso del

134 Zaida Liz Patiño Gómez 
Estado y la sociedad civil para su consecución. Para traspasar el umbral que nos separa del alcance de los ideales se requiere de un proyecto político de largo alcance y planificado a largo plazo. Edificar un nuevo proyecto de sociedad pasa por la puesta en marcha de un proceso educativo que enseñe a ser ciudadanos desde el preescolar hasta el doctorado; que depure los estamentos estatales y el mismo ámbito político de los factores que han sido identificados como negativos y que van en contravía de la realización del nuevo proyecto.

Por último, el Espacio Público se debe constituir como el espacio para la formulación y desarrollo de la nueva propuesta, debe constituirse como dice Rabotnikof (1993:90) en "ámbito de discusión, de debate y de argumentación públicamente desarrollada. Por lo tanto debería ser, en reversión progresista del diagnóstico sobre la 'sobrecarga' del Estado, canal o instancia de descongestionamiento de 'poderes y demandas que pasan a ser autoadministradas por la comunidad, sin transformarse en el 'mundo de la mercancía'. Lo público sería lugar de expresión de una sociedad civil plural, de sus aspiraciones, valores, relaciones de fuerza (...). Desde el punto de vista de la ciudadanía, esta no sólo se expresaría en el pleno ejercicio de los derechos políticos, sino que se 'ampliaría' a prácticas de participación en la gestión y administración que parecen conectar con una idea más activa de la ciudadanía social".

\subsection{La reivindicación del Espacio para lo público}

La ciudad no solamente son edificios, calles, parques, comercio; también es gente. Es una aglomeración poblacional de carácter muy diverso y esto, ante todo, significa la concentración de referentes e imaginarios diferentes. Esta diferencia enriquece la ciudad, le da su significado pluralista y multicultural, pero a la vez plantea una pregunta, la pregunta fundamental, aquella sobre ¿cómo vamos a vivir juntos? Responder esta inquietud implica restituir la sociedad, poner en práctica una revolución cultural y política.

Ejercer la ciudadanía participando activamente en la construcción de la nación que queremos redundará directamente en la nueva ciudad, porque hacer sociedad es hacer ciudad. Lo mismo sucede con la pregunta sobre ¿cómo vivir juntos?, no se limita a su resolución en el entorno urbano sino que se extrapola a la nación entera. Colombia es un país sin cohesión social, con un territorio fragmentado y fuertes descargas de violencia donde el ejercicio de hacer ciudad-sociedad se convierte en un camino para dar al traste con estos aspectos negativos, más aún cuando parece estar está destinado que la mayoría de la población viva en núcleos urbanos.

El Espacio Público se instituye de esta forma como continente de aquellas manifestaciones diversas, de los referen- 
tes e imaginarios de todas aquellas apuestas culturales que desean soñar y realizar la nueva ciudad.

El Espacio Público se debe entender en su doble acepción: como ámbito físico concreto y como concepto jurídico-político abstracto. En el primer sentido, es el lugar para el disfrute, para el paseo, para el encuentro y la contemplación. En su segunda acepción, es el espacio para el ejercicio de la democracia, para el intercambio y la propuesta. Para Delgado (2001:34) “el Espacio Público es lo que se halla en las antípodas de lo cristalizado, de lo fijo, puesto que es el ámbito de las ocupaciones efímeras y de las circulaciones". No obstante, no sólo por ser un espacio de flujos es la antítesis de lo fijo, en su sentido jurídico político, por ser ámbito del ejercicio de la ciudadanía como democracia, es un espacio que se autoinstituye de forma continuada. En palabras de Castoriadis (1999:148) "esto no significa que cambie de constitución cada mañana o cada primero de mes; significa que ha tomado todas las medidas necesarias, de derecho y de hecho, para poder cambiar sus instituciones sin guerra civil, sin violencia, sin derramamiento de sangre. Por supuesto, nadie puede garantizar que la violencia sea desterrada para siempre de la historia humana si se instaura la democracia".

La doble concepción del Espacio Público redefine la noción misma de la relación público-privado. Lo público es reivindicado para la afirmación mis- ma de la ciudadanía en el ámbito de lo común. El asumirse individualmente en un espacio colectivo permite reafirmarse frente al otro con el que comparto los mismos derechos, deberes y espacio, y potenciar la capacidad que estas dos apuestas (la del otro u otra y la propia), en tanto diferentes, aportan al enriquecimiento mismo de la sociedad, reproduciéndola bajo el principio del respeto, la valoración, el entendimiento y la tolerancia.

En el Espacio Público se da una nueva identidad a lo individual, lo potencia y enriquece al enfrentarlo a la otredad. Siendo el ámbito de la sociedad civil, es también el ámbito de la realización individual porque en él se despliega el pensamiento y la propuesta. Para Viviescas $\left(1996^{\mathrm{a}}: 169\right)$ "a partir de aquí, lo privado no es ya más simplemente lo que se tiene: la propiedad privada. Mucho más allá, es lo que autónoma y libremente dispone cada ciudadano para aportar a la construcción de lo colectivo; más aún: es el punto desde el cual cada individuo ve, critica y contribuye a construir, a vigilar, a fiscalizar lo público, es el punto de apoyo para su participación colectiva".

Se hace necesaria una política que aboque a su construcción tanto física como cultural, que lo reivindique como sustento fundamental de la sociedad; que lo singularice frente a los otros atributos urbanos públicos (vivienda, servicios públicos, transporte, suelo urbano) resaltándolo como el único capaz

136 Zaida Liz Patiño Gómez 
de propiciar la refundación misma de la ciudad; que propenda por la garantía de su construcción si se pretende reproducir una sociedad democrática: inclusiva en lo político, equitativa en lo social, competitiva en lo económico y sustentable en lo ambiental; que sea capaz de responsabilizar a cada uno de los sectores que deben comprometerse con su reflexión, construcción, administración y mantenimiento (sociedad civil, el sector privado, las ONG, la academia y el Estado), así como definir los niveles de participación de cada uno.

Quedan por último dos aspectos esenciales que hacen posible y legitiman la existencia del Espacio Público, el primero lo constituye la educación, la institucionalización de una forma diferente para entender la vida individual y colectiva, el agenciar la revolución misma de la participación política, la transformación socio-cultural necesaria que, orientada con los preceptos democráticos, concientizará acerca de la necesidad misma de la construcción del Espacio Público para el nuevo proyecto de sociedad.

El segundo, resultado del anterior, se refiere a la condición de la "introyección en el imaginario colectivo" de la urgencia del Espacio Público, porque como señala (Viviescas, 1996b:210) "en Colombia, hasta ahora y de manera general podemos decir que se puede vivir sin el Espacio Público, sin su consideración como parte integrante de la ciudad y de su existencia (...) Por estar dedicados a agenciarse la manera de garantizar la sobrevivencia diaria, no cabe la formulación de la calidad espacial como parte de sus aspiraciones y reivindicaciones, por lo cual nunca aparece a nivel colectivo la necesidad de construir una espacialidad para la creatividad, la recreación, el encuentro ciudadano y la contemplación estética, con la consecuencia de que ella nunca se construye y la baja calidad espacial de la ciudad se profundiza y extiende".

\section{Aproximación a la producción geográfica en Bogotá}

Se realizó un primer acercamiento al estado del arte de la producción geográfica urbana en Bogotá. Fueron consultadas las investigaciones realizadas en el pregrado del Departamento de Geografía de la Universidad Nacional; la producción de la Maestría en Geografía -EPG- convenio Universidad Pedagógica y Tecnológica de Colombia-Instituto Geográfico Agustín Codazzi; la biblioteca del Instituto Geográfico Agustín Codazzi -IGAC- y la producción de la Licenciatura en Educación básica con énfasis en Ciencias Sociales y de la Maestría en Docencia de la Geografía de la Universidad Pedagógica Nacional.

En Colombia el proceso de institucionalización de la Geografía se emprendió a partir de 1967 con la crea- 
ción de la Asociación Colombiana de Geógrafos (ACOGE), en la cual participaron algunos profesionales de esta disciplina, formados primordialmente en el extranjero, así como autodidactas interesados en la misma. Tal proceso se afianzaría en 1984 con la apertura de la Maestría en Geografía, fundada por la Universidad Pedagógica y Tecnológica de Colombia (UPTC), en convenio con el Instituto Geográfico Agustín Codazzi (IGAC), a la cual en 1997 se le asigna el énfasis en Ordenamiento Territorial, obedeciendo a las transformaciones socio-políticas que atraviesa el país en el actual momento histórico.

En 1993 se inicia la carrera de Geografía en la Universidad Nacional de Colombia, evento que surge a la par con la expedición de la Ley 78 de 1993, que reglamenta la profesión de Geógrafo. Dicho proceso es aún incipiente en el país por lo cual la Geografía no ha adquirido el estatus que le ha sido reconocido en otras latitudes en los ámbitos académico, social y político.

Dado el carácter reciente del proceso de profesionalización de la disciplina, se pretendió identificar las tendencias de investigación de las y los nuevos geógrafos que están siendo formados en la disciplina. Dentro de este proceso, la creación de la Maestría en Geografía Convenio UPTC- IGAC se constituye en un hito, por tal motivo, se consideró la revisión de los trabajos de grado presentados al Programa.
Esta mirada sobre la producción de la Maestría en Geografía -EPG- se fundamenta en una primera aproximación que se desarrolló en el artículo Estado Actual de la Geografía: la investigación en el programa de estudios de Posgrado en Geografía (Martínez y Patiño, 2000).

Después de la revisión de las 58 tesis analizadas para el año 2000 se concluyó lo siguiente: En primera instancia, es importante señalar que al contrario de lo que podría pensarse, la Geografía Física no es la dominante dentro del quehacer geográfico, es más, sorprende el hecho de que se han ampliado significativamente los horizontes de investigación, dando paso a un intento por abordar los problemas desde una visión de conjunto.

Si bien, la exploración de nuevos temas desde una perspectiva de investigación integral, que aspira revalorar la interacción seres humanosmedio ambiente, pretende interpretar la realidad bajo una visión más humanista y menos sujeta a leyes establecidas, privilegia precisamente el análisis cuantitativo, muchas veces insuficiente para el abordaje de dichos temas.

Persiste en la investigación geográfica del la maestría la escasa discusión teórica alrededor del objeto de estudio de la disciplina, elemento esencial para la consolidación del cuerpo teórico de la disciplina. 
Por otro lado, la Geografía Espacial entendida como el estudio de la variación del espacio en el tiempo-, a pesar de haber cobrado importancia, no discute el concepto de espacio como producción social, sino que este aún es concebido como el escenario donde se suceden variaciones físicas.

Desde la perspectiva del Espacio Público, de interés de esta investigación, no se encuentra enmarcado ningún trabajo monográfico en la Maestría -EPG-.

En el Departamento de Geografía de la Universidad Nacional se encontraron referenciadas 23 tesis de pregrado , de las cuales, siete tienen que ver con el tema del espacio urbano. No obstante, sólo cuatro de ellas pudieron ser revisadas ya que no fue posible ubicar las otras ni en el Centro de Documentación ni en la Biblioteca Central de la Universidad.

De las cuatro tesis revisadas, dos tienen que ver con el espacio colectivo de la ciudad. La primera, elaborada por Vladimir Melo Moreno (1998) se titula La Calle: Espacio Geográfico y Vivencia Urbana en Santafé de Bogotá, desarrolla elementos que se aproximan a la perspectiva de interés de esta investigación. Se plantean aspectos del imaginario colectivo de la ciudad, rescatando la espacialidad desde la cotidianidad de los habitantes de la ciudad. Igualmente en esta investigación se desarrolla una elaboración del concepto de espacio en la perspectiva de la geografía. Se puede considerar esta tesis como un aporte a la comprensión de un espacio público como la calle, teniendo en cuenta el lenguaje como primer elemento de la construcción social del espacio o de cualquier construcción social (Melo, 1998).

La otra tesis que trabaja el espacio colectivo de la ciudad se denomina Desde la Plaza de las Hierbas hasta el Eje Ambiental, elaborada por Hernando Arenas (2000). Esta monografía desarrolla un recorrido histórico por la conformación espacial de la Av. Jiménez para sustentar la hipótesis de la dialéctica de los pares, que trata sobre la competencia espacial entre usos del suelo afines.

Se identifican en ella algunos elementos afines con esta investigación, sobre todo desde la invitación a abordar de manera compleja el problema de la ciudad, superando la mirada restringida que predomina en su análisis.

En la Licenciatura en Educación básica con énfasis en Ciencias Sociales y la Maestría en Docencia de la Geografía de la Universidad Pedagógica Nacional se han producido 92 monografías, 34 de las cuales se elaboraron en la Maestría (Anexo2).

Dado el carácter pedagógico de esta universidad, se desarrollan en su mayoría trabajos aplicados al ambiente educativo. No obstante, se haya una reflexión importante sobre el espacio como producto social, referido al estudio de casos. 
De los títulos revisados, específicamente sobre la espacialidad en Bogotá se destacan:

- Hacia la Construcción del concepto de ciudad: Experiencia pedagógica en estudiantes de noveno grado. ROCHA, José Eduardo. 1994.

- El Concepto de Espacio Geográfico Urbano: Una construcción en el aula. RÁQUIRA, Osorio Ana. 1996.

- La ciudadanía de mundo. Entre exigencias sociales y representaciones. CASTRO BOHORQUEZ, Gloria 1995.

Específicamente sobre el tema del Espacio Público no se encontraron referencias.

En la Biblioteca del Instituto Geográfico Agustín Codazzi -IGAC- no se encontraron publicaciones sobre desarrollo de investigaciones desde la perspectiva aquí señalada.

\section{El espacio público y el Plan de Ordenamiento Territorial -POT- de Bogotá}

Bogotá es el asentamiento urbano de mayor predominancia a nivel nacional, alberga cerca de 7 millones de habitantes y concentra la mayor parte de la actividad comercial del país, sobresaliendo respecto a otros centros urbanos como Medellín o Cali.
El POT se convierte -como la misma administración lo denomina- en la "carta de navegación" con que cuenta Bogotá para reordenar su territorio, sus actividades, el uso que los ciudadanos le dan al suelo y su tratamiento, así mismo orienta la inversión pública y privada con miras a mejorar la calidad de vida de los habitantes en los próximos 10 años.

El siguiente aparte contiene una reflexión acerca del proceso de participación ciudadana como ejercicio de ciudadanía en el POT de la ciudad. Proceso entendido no sólo como el pleno ejercicio de los derechos políticos (sufragio), sino extendido a las prácticas de participación en la gestión y administración, sentido asociado a la idea de una ciudadanía social. Se analizará igualmente la concepción misma de la cual parte la administración para evaluar y delinear el componente de Espacio Público.

El POT ha sido resaltado por la administración distrital como la posibilidad de recuperar la tarea de planificación del territorio y desarrollar nuevos instrumentos de ordenamiento, dirigidos a solucionar los problemas que el desarrollo urbano acelerado y conflictivo ha acumulado sobre su territorio. Agreguemos a estas condiciones la hegemonía de unas prácticas anquilosadas de hacer política que no han permitido potenciar en toda su capacidad las cualidades de la ciudad, junto con la ausencia de una que dentro de su ética propenda por 
asentamientos cualificados para la vida humana, que no obedezcan simplemente a la finalidad de la rentabilidad económica.

La carta de navegación de Bogotá no podía alejarse de los preceptos que en el marco de la Cumbre de Estambul se delinearon como fundamentales para el desarrollo de las ciudades: vivienda adecuada para todas y todos, asentamientos humanos sostenibles, participación, igualdad entre hombre y mujer, financiación de la vivienda y los asentamientos humanos, cooperación internacional y evaluación de los progresos.

Estos compromisos son realizables en la medida que se parta de la implementación de transformaciones de fondo en la sociedad colombiana. Son cambios sustanciales que implican la revolución en la forma en que hasta ahora han sido planificadas nuestras ciudades, los instrumentos y métodos utilizados; pero implica necesariamente el liderazgo de un proceso de renovación cultural bajo una orientación democrática y participativa.

Por eso es tan importante que el Ordenamiento Territorial haya sido asumido "como una labor a largo plazo", pero desafortunado el hecho de que no se adopten en el POT disposiciones ni normativas (de carácter obligatorio) ni operativas (acciones)- tendientes a generar el cambio cultural necesario para alcanzar los objetivos propuestos. Más allá de las disposiciones físicas dentro del territorio, que buscan "una visión de conjunto de la ciudad", no se piensa en las acciones necesarias para lograr la revolución cultural que implica su construcción.

Garantizar la sostenibilidad del desarrollo debe estar cubierto, pero debe ser vislumbrado como un aspecto más de un todo complejizado que es la ciudad. La ciudad debe enriquecer la existencia de los seres humanos, permitir el desarrollo armonioso con la naturaleza, pero también propender por la generación de formas de respeto con sus semejantes, con los otros y otras que comparten el mismo espacio de vida.

En el Documento Técnico de Soporte (2000), la administración parte de que la dificultad en la construcción de lo público en la ciudad se refiere al deterioro de su soporte físico colectivo, que se manifiesta en el abandono del Espacio Público y en la omisión de la importancia del patrimonio cultural inmueble y de los espacios y edificios públicos en la estructuración de la ciudad. Asume el deterioro de lo público como la incapacidad de la sociedad para identificarse con las singularidades de la ciudad, la imposibilidad de construir y reconocer los valores colectivos, la legitimidad del otro y de sus intereses y, finalmente, la negación de una posible instancia que represente las reglas de control social y solución de conflictos.

Es una lástima que en un documento como el POT -que pretende marcar un 
hito en la planificación y gestión- la administración no asuma la responsabilidad que recae en ella resultado de su incapacidad para generar la reivindicación de lo público en los propios ciudadanos y resuma todo en la "naturaleza negativa y corrupta" de estos últimos, causantes directos del "deterioro de lo público". No siendo suficiente con esto, se pretende continuar con la miopía que impide asumir el Espacio Público de manera compleja y lo reduce simplemente a su aspecto físico, prolongando los errores que el rezago cultural y político de nuestra sociedad plasma en la Bogotá de hoy.

La limitada visión de la administración asume la construcción, renovación o conservación de infraestructuras físicas, en sí mismas, "facilitan la convivencia", rescatan la memoria y "llenan de significado" la vida urbana.

Sin embargo, superar lustros de ausencia de pensamiento de la ciudad, de negligencia en las prácticas de las disciplinas que hasta ahora la han edificado y de un vacío total de participación ciudadana no se logra simplemente con erigir edificios públicos con espacios libres a su alrededor, ni colocando bolardos ni construyendo más parques o renovando y/o conservando el patrimonio. Si bien se constituyen en aspectos importantes, se hace imperioso complementarlo con acciones tendientes a educar a la ciudadanía en la participación, y no sólo a ella sino a todos los estamentos -sociedad civil, estado y empresa privada- que están llamados a hacer parte de este proyecto. Se requiere igualmente aunar esfuerzos, definir responsabilidades y concientizar de su importancia a la comunidad. Implica también superar la visión simplista a través de la cual la administración concibe al Espacio Público, esa que no ha podido relevarlo en toda su potencialidad.

Como se ha pretendido resaltar en este trabajo, el Espacio Público es el ámbito en el cual, cualquier intento por proyectar una nueva ciudad, se hace posible. Porque su doble carácter -físico y cultural- propicia las condiciones para el encuentro de las diferentes apuestas culturales que piensan y viven en la ciudad, ellas que la conocen y que, mediante el poder de la palabra, la discusión, el consenso y la negociación son capaces de hacer realidad la utopía de ciudad.

\subsection{El POT y la participación ciudadana}

La administración procuró en las fases de diagnóstico, formulación, seguimiento y evaluación del POT la consulta y participación democrática, mediante mecanismos de "comunicación y convocatoria". Como se lee en el Documento Técnico de Soporte (2000:744), el objetivo final fue "lograr que la población no sólo comprenda y entienda el Plan, sino que se identifique con él $y$, de manera organizada, desarrolle sus contenidos y acompañe y verifique la realización de los proyectos previstos", trabajo que se 
desarrolló a través de talleres, encuestas, exposiciones. No obstante, hubo fallas en su concepción y aplicación que redundan en la cualificación del instrumento.

Democracia que refiere a la igualdad como "posibilidad real de participación de todos y cada uno, evidentemente no sólo se habla de la posibilidad de acceso a la información. Se habla tanto de la capacidad real de juzgar -lo que lleva directamente a la cuestión de la educación- como del tiempo necesario para la información y la reflexión -lo que así mismo lleva directamente a la cuestión de la producción y de la economía. Por otra parte ante el desencadenamiento de la demagogia y la sofística contemporáneas, es necesario recordar que se trata de igualdad política, de igualdad de participación en el poder" (Castoriadis: 1999: 150). Bajo esta óptica se puede afirmar que la planificación en Colombia ha invisibilizado al ciudadano, y que hoy, cuando la ley ordena que sea él en su soberanía el artífice de su desarrollo, el Estado ha de asumir la responsabilidad enorme de desatrasar y destrabar el imaginario colectivo de la sociedad, porque décadas de invisibilidad no se superan si no es a través de un esfuerzo educativo a largo plazo.

Una democracia sin ciudadanía que ejerza sus derechos no es democracia. Una población que no tiene un espacio cualificado para ser y existir en su cotidianidad, en su cosmovisión, no será una ciudadanía democrática. No se sensibilizará por los problemas de las y los otros porque simplemente no los conoce, porque no se ha creado un espacio para que debata con otras cosmovisiones. Sin un Espacio Público cualificado, percibido en su integralidad no podrán ser resueltos los problemas que acusan a la sociedad capitalina y nacional, simplemente porque una sociedad que no participe en su desarrollo seguirá produciendo exclusión, inequidad, violencia y demás consecuencias negativas que hasta ahora caracterizan el país.

El proceso de participación de la comunidad en el POT de Bogotá se desarrolló en cuatro fases, en las cuales se identificaron deficiencias específicas que tienen que ver no sólo con la conceptualización del espacio urbano, específicamente el Espacio Público por parte de la administración, sino con factores inherentes al mismo proceso y que redundan en la cualificación del POT de la ciudad, por tanto en el futuro mismo de la existencia de los cerca de siete millones de habitantes. Ellas son:

- La ausencia de legitimidad del Estado frente a los temas públicos redundó en un bajo nivel de convocatoria de la ciudadanía que poco se interesó por el tema del ordenamiento territorial.

- La inexperiencia del DAPD frente a un tema como la convocatoria ciudadana, dado el carácter técnico que prima en su configuración interna. 
- Se convocó primordialmente a los gremios, a los Ediles y sociedad organizada, pero no se desarrollaron estrategias para involucrar a la ciudadanía no organizada -que representa una mayor población- más allá de exposiciones itinerantes cuyo impacto no es fácil estimar. En este sentido las ciencias sociales están llamadas a cualificar las metodologías de participación ciudadana que abogue por una real convocatoria, por una mayor intervención de la sociedad en un tema que grandes repercusiones en la existencia.

- Otro factor que redundó negativamente en el proceso de participación ciudadana fue el tiempo. Si bien es cierto que la tarea de ordenar el territorio no da espera, es importante comprender que el trabajo con la comunidad implica unos ritmos particulares muy diferentes del tiempo manejado por los planificadores. De esta forma, no es ilógico pensar que a costa de la premura del tiempo se sacrificaron elementos, actividades, metodologías que hubieran contribuido a cualificar la participación ciudadana.

- La ausencia de sensibilización sobre el ordenamiento territorial y su importancia para la planificación y el desarrollo futuro de la ciudad incidieron en el bajo interés demostrado por la ciudadanía.
- Al ser la participación ciudadana un tema novedoso no se presentaron resultados a corto plazo ni concretos.

- La competencia de saberes. La ausencia de sensibilización de los profesionales de la rama técnica frente a la importancia de la participación ciudadana en la planificación.

- El bajo nivel de convocatoria de los representantes de la comunidad como Ediles, Alcaldes locales y sociedad organizada.

- Ausencia de un acompañamiento continúo por parte de la administración. Tal es el caso de la Localidad de Chapinero, donde la activa participación de la alcaldía local permitió una mayor difusión y participación de la comunidad. No obstante es el Estado el que debe garantizar que la planificación sea participativa, no depende solamente de los esfuerzos de unos pocos de la comunidad que estén más interesados en el tema, sino que se debe propender por estrategias que superen estas limitantes, lo cual debe ir paralelo con el acompañamiento $\mathrm{y}$ orientación de la administración.

Aún con sus deficiencias, el diseño y la aplicación de los POT debe ser considerado como la continuación del camino, inaugurado por la Constitución Nacional de 1991 y afianzado por la Ley 388 de 1997, para lograr una nación democrática y moderna. 


\section{Conclusiones}

En el Plan de Ordenamiento de Bogotá no se tuvieron en cuenta elementos desarrollados por la geografía urbana en el mundo, los cuales tienen una incidencia real sobre la planificación de la ciudad, y que hubieran permitido cualificar este instrumento, redundando en una mayor calidad de vida para la gente.

Al indagar sobre la producción geográfica respecto a los elementos que la teoría social ha desarrollado sobre la cuestión urbana, se encuentra que la disciplina ha aportado poco en la discusión sobre el tema del espacio urbano en Colombia, específicamente sobre el planeamiento territorial de la metrópoli del país, Bogotá. Falencia preocupante hoy cuando es una disciplina que ha ido ubicándose -en su desarrollo epistemológico y el de sus herramientas técnicas- en el umbral de las ciencias sociales contemporáneas.

Es necesario generar un proceso de investigación y de producción de conocimiento, y de difusión de la geografía en Colombia, para que efectivamente se pueda cumplir ese papel que la geografía está llamada a asumir, para cualificar el acercamiento al problema urbano y por ende de su forma urbana.

Existe una limitada visión de la administración respecto al Espacio Público que lo limita a su sentido físico en detrimento de su complejización jurídico política.

Proponemos ampliar la visión sobre el espacio público que lo identifica con una imagen física del espacio, neutra, estática, concreta; por una que lo revalore en su doble acepción: física y jurídico- política, elemento -este último- que implica diversidad, heterogeneidad; que es un caleidoscopio de visiones e imágenes de ciudad. Entonces, el espacio público es entendido como ciudadanía, como una condición fundamental para ser y ejercernos como ciudadanos.

Aportar una mirada desde la geografía sobre un elemento como el espacio público apunta a contribuir en una reflexión que disciplinas del espacio como la Arquitectura y el Urbanismo están suscitando en la actualidad. 


\section{Bibliografía}

BORJA SEBASTIA, Jordi. “Ciudadanía y Espacio Público". En: Bogotá Sostenible. Publicación Seriada. Bogotá: Alcaldía Mayor de Santa Fe de Bogotá. Documento sin fecha.

CASTELLS, Manuel. La sociología y las masas. Sociología de los movimientos sociales urbanos. Madrid: Alianza editorial, 1986.

CASTORIADIS, Cornelius. Figuras de lo Pensable. Madrid: Frónesis Catedra Universitat de València, 1999.

-__-La Democracia como Procedimiento y como Régimen. En: Ciudadanos sin Brújula. México: Ediciones Coyoacán, 2000.

CASTRO BOHORQUEZ, Gloria. La ciudadanía de mundo: Entre exigencias sociales y representaciones. 1995. Trabajo de Grado (Magister en Docencia de la Geografía) Universidad Pedagógica Nacional. Facultad de Artes y Humanidades. Departamento de Ciencias Sociales. Maestría en Educación con Énfasis en Docencia de la Geografía.

CÁTEDRA MANUEL ANCIZAR. La Ciudad: hábitat de diversidad y complejidad. Bogotá: Universidad Nacional de Colombia, 2000.

CONGRESO COLOMBIANO DE GEOGRAFIA. Memorias. Bogotá: Ed. Guadalupe, 1988.

CUMBRE DE LAS NACIONES UNIDAS SOBRE LA CIUDAD. Agenda HABITAT II. Documento de Internet. www.undp.org/un/habitat/agenda/español

DELGADO, Manuel. La Disolución de las Identidades. Espacio Público y Derecho a la Indiferencia. En: ASTRAGALO. Cultura de la Arquitectura y la Ciudad. Espacios, migraciones, alteridades. No. 18. Pp. XXXIII-XLVI. Bogotá: Celeste Ediciones, 2001.

GIRALDO, Fabio. la Política Urbana en el Salto Social. Ciudades y Ciudadanía. En: Foro Económico. No. 1. Año 1. Bogotá Octubre de 1995.

146 Zaida Liz Patiño Gómez 
GIRALDO, Fabio y VIVIESCAS, Fernando (Comp.). Pensar la Ciudad. Bogotá: Tercer Mundo Editores/ CENAC/FEDEVIVIENDA, 1996.

HARVEY, David. La Condición de la Posmodernidad. Investigación Sobre los Orígenes del Cambio Cultural. Buenos Aires: Amorrortu editores, 1990.

-Urbanismo y Desigualdad Social. Madrid: Siglo XXI Editores, 1977.

LEFEBVRE, Henri. La revolución urbana. Madrid: Alianza editorial, 1983.

LEZAMA, José Luis. Teoría Social, Espacio y Ciudad. México: El Colegio de México, 1993.

MARTINEZ, Sandra y PATIÑO, Zaida. Estado Actual de la Geografía: la investigación en el programa de estudios de Posgrado en Geografía, convenio UPTC-IGAC. En: Perspectiva Geográfica. No. 6. Bogotá, 2000.

RABOTNIKOF, Nora. Lo Público y sus Problemas: notas para una reconsideración. En: Revista Internacional de Filosofía Política 2. No. 2. Madrid, 1993.

RAQUIRA OSORIO, Ana M. El concepto de espacio geográfico urbano. Una construcción en el aula. 1996. Trabajo de Grado (Licenciada en Ciencias Sociales)) Universidad Pedagógica Nacional. Facultad de Artes y Humanidades. Departamento de Ciencias Sociales.

RED DE ESTUDIOS DE ESPACIO Y TERRITORIO (RET). Espacio y Territorios. Razón, pasión e imaginarios. Bogotá: Universidad Nacional de Colombia, 2001.

ROCHA, José Eduardo. Hacia la construcción de concepto de ciudad: Experiencia con estudiantes de noveno grado. Santafé de Bogotá, 1994. Trabajo de Grado (Magister en Docencia de la Geografía) Universidad Pedagógica Nacional. Facultad de Artes y Humanidades. Departamento de Ciencias Sociales. Maestría en Educación con Énfasis en Docencia de la Geografía.

SANTOS, Milton. La Naturaleza del Espacio. Técnica y Tiempo. Razón y Emoción. Barcelona: Ariel Geografía, 2000.

____-Metamorfosis del Espacio Habitado. Barcelona: Oikos Tau, 1996.

ALCALDÍA MAYOR SANTA FE DE BOGOTÁ. Decreto Número 619 de 2000. Documento Técnico de Soporte. Bogotá: Imprenta Distrital, 2000.

VIVIESCAS MONSALVE, Fernando. La Ciudad: La calidad del espacio para la Vivencia. En: Pensar la Ciudad. Bogotá: Tercer Mundo Editores/ CENAC/FEDEVIVIENDA, 1996ª . 
- La Agenda HABITAT II. En los Fundamentos para la Formulación de una Política de Espacio Público (Leyendo la Cumbre de Estambul desde Colombia) En: Ensayo y Error Revista de Pensamiento Crítico Contemporáneo. No. 1, Año 1. Bogotá, Colombia, 1996b.

Espacio Público. Imaginación y Planeación Urbana En: Documentos Barrio Taller (Serie Ciudad y Habitat) La Calle. Lo ajeno, lo público y lo imaginado. Bogotá: Barrio Taller, 1996c.

UNWIN, Tim. El lugar de la geografía. Fotocopias. 1992.

148 Zaida Liz Patiño Gómez 